\title{
Accounting for employment generation and expansion: A tool for insecurity in Nigeria
}

\author{
K. M. Makinde*, A. O. Ayegbokiki and O. A. Sotunde \\ Institute of Food Security, Environmental Resources and Agricultural Research (IFSERAR), Federal University of \\ Agriculture, Abeokuta, Nigeria.
}

Accepted 13 August, 2013.

\begin{abstract}
An enduring outcome of observation processes is the enduring visibility of the need for the generation and expansion of employment. The current situations in Nigeria are underemployment, unemployment as well as insecurity. Among the broad causes of unemployment are absence of industrialization, poor agricultural system, high cost of qualitative education, rapid population growth, rural-urban migration in search for white collar job, mismatch between required and acquired skill and poor data base. The focus of this paper is to account for and recommend ways of employment generation and expansion on the one hand and proffer a panacea for insecurity on the other, the assumption is that, employment generation should be on the priority list of any government on policy formation as well as the expansion, continuity and sustainability of the generated employment in general and improvement on low agricultural produce in particular. Therefore, it is however recommended that improvement on low agricultural output, technology transfer and Empowerment of Small and Medium Scale Enterprises (SMEs) or entrepreneurship should be critically taken attention to, to generate employment and as well curb the insecurity situation in Nigeria.
\end{abstract}

Key words: Absolute and comparative cost advantage, entrepreneurship, insecurity, low agriculture, technology transfer.

\section{INTRODUCTION}

It is widely believed that regardless of level of development (under-developed, developing, developed or advanced) every country must have passed through one stage or phase of the developmental processes or the other. As it is always quoted "how could we go further if we disregard where we are coming from? Hence, the need to beam and focus our search light unto the meaning of unemployment, causes of unemployment, effect of unemployment and the ways to expand employment to security challenge in Nigeria.

There is no way we could be talking about employment generation and not mentioning unemployment as the root of employment generation. However, after employment generation, we now look on how we can sustain and expand such employment generated.

Taking a cue from what the government of Malaysia, Philippine, Mauritius, Pakistan, India, South Korea, Thailand and many of the Newly Industrialized Countries (NICs) did, policies and programmes that integrate domestic Small and Medium Scale Enterprises (SMEs) into the mainstream of industrial development through provision of critical inputs that enable them to expand their market internationally; championing new openings in the export markets for the product of SMEs, devotion of lending portfolio to micro, cottage, small, medium and industries as well as close government-private sector initiative that made this sub-sector account for over $80.0 \%$ of total employment and contribute not less than 
$30.0 \%$ to GDP annually (Etim, 2010). From the above, it is deduced that the countries mentioned, passes through one or more developmental stages to arrive at where they are today. Hence, the need to borrow a leave from the NICs, their focus areas however, were: Policies and government; which is the major problem Nigeria is facing presently, new openings of the SMEs product; They are nowhere to be found in Nigeria, devotion of lending of portfolio to micro, cottage, small and medium industries; This is done at the highest rate in Nigeria, Close Government-private sector initiative; Powers and decisions are centralized to the president that is a lot of powers are too much delegated to the Presidency; hence, this should be controlled by decentralizing powers to the state Governors, and $80.0 \%$ expansion of employment and contribute $30.0 \%$ to GDP annually.

However, the International Labour Organization defined unemployed as a number of the economically active population who are without work but available for and seeking work including people who have just lost their jobs and those who voluntarily left work (World Bank, 1998). Also, unemployment is said to be stock of all those individuals who are not engaged in any productive activity and who are either unable to find work at the prevailing real wage rate or who are in the process of switching to a new job. It also means a situation in which people who are qualified, able and willing to work are currently without any paid job. The increase in unemployment rates make people to find job in the informal sector of the economy. Wakil (2012), reported that, unemployment is widespread in Nigerian urban areas.

Consequently, the causes of unemployment are not limited to the following: Absence of Industrialization, Poor Agricultural system, High cost of qualitative education, Rapid population growth, Rural-urban migration in search of white collar job, Mismatch between required skill and acquired skill and Poor data base. Thus, the effects of unemployment are: Increase in crime rate (Social implication), Under-utilization of human resources, thereby making economic development of affected nations, increase in dependents and poverty, encouraging education and training of manpower and reduces national output aggregate savings and national income. Therefore, the above causes and effect of unemployment are discussed below under three headings to expand employment and as well deal with insecurity in Nigeria, viz: "low Agricultural produce, Technological Transfer and Entrepreneurship.

\section{Low agricultural produce}

Nigeria has acquitted food shortage that on occasions has been dangerously dependent on food imports for the welfare of its people. It agricultural sector has ceased to be an important contributor to foreign exchange earnings; even its contribution to employment has decline. This situation has not always been so and in fact, there is a great national optimism that the current predicament would be reversed and in Nigeria and return to full status of a major food basket in the Region (Nosiru, cited in Alademerin and Odusina, 2009).

Nigeria is fortunate with its geography. It has a fair share of land that is moderate in its geographical extremes, well watered by rains, river-systems and under-ground water reservoirs; most of the country is arable. The vegetation varieties endow the country with capability to undertake the successful cultivation of a wide range of crop types. The climate is thankfully clement most of the year. There are enough resource materials to manufacture inputs to augment the richness of the soil: there is enough of human capital to tap from to the full of the soil, and its institutions of learning and research have engaged in commendable efforts in developing and adopting new crop variants that give greater yields and survive the teeming tropical pests, with all these attributes the Nigeria agricultural sector which has the potential to generate employment has been neglected. Although the government has been making attempt to revive the agricultural sector by developing many agricultural programmes; but it will end a up on desk of the policy formulator

\section{Some government programmes related to agriculture}

(1) The Agricultural Development Programme (ADPs)

(2) The National Agricultural Land Development Authority (NALDA)

(3) The Strategic Grain Reserves Programme (SGRP)

(4) The Programme for Accelerated Wheat Production (PAWP)

(5) The Development of Artisanal Fishing, Small Ruminant Production (DAFSRPPGR)

Furthermore, these programmes promote utility of land resources through subsidizing land development, supply of farm inputs and services and credit extension to farmers and as well as institutional support for producing marketing cooperatives.

\section{Way forward in improving agricultural sector}

During the colonial and the immediate post-colonial era, regional government and major trading companies established and operated extensive cash crop plantations, and grew such tree crops as oil palm, cashew, rubber and even timber trees like teak, gmelina. The worldwide fall in prices of primary produce resulted in near abandonment of these estates and plantations (Alademerin and Odusina, 2009). But as Nigeria's economic fortunes have turned in cycle, much attention is being paid to the rehabilitation of these estates and 
plantations, and the development of new ones. Most estates plantations and estates are being put up for outright sale or long management lease to private investors/enterprises. That is the reason why this paper is focusing on agriculture as one of the panacea, especially the food crops to expand employment generation and as well solve the security menace in the country.

At this juncture, we need to borrow a leave from the international trade principles by narrowing down these principles to home trade of Nigeria Regions, viz; Principle of absolute cost advantage and Principle of comparative cost advantage.

\section{Absolute cost advantage}

This principle was propounded by Adam Smith. He stated that nations should specialize in the production and exportation of commodities in which she has absolute advantage and import the commodity in which it has absolute disadvantage (Dominick and Eugene, 1996). This is illustrated in Table 1.

North Central (consisting of Seven (7) States; Benue, Federal Capital Territory (FCT), Kogi, Kwara, Niger, Nassarawa, and Plateau) has absolute advantage in the production of Rice, Sugarcane and Tomato i.e. virtually all the states in North Central Region produces all the above mentioned crops while other regions has absolute disadvantage, likewise the North West(Wheat, cotton, Groundnuts and Jatropha), South East (Oil palm), South West (Cocoa and Cassava) and South South (Rubber). What this implies is that the region that has absolute advantage of Agricultural Commodities to other regions should focus and specialize in that commodity(s). Therefore, the crops which Nigeria should focus and specialized on are shown in Figure 1.

\section{Comparative cost advantage}

This theory was put forward by David Ricardo. It states that even if one country has absolute advantage in the production of two commodities, the country will be better off, if each country specializes in the production of the commodity in which it has greatest comparative advantage over the other (Dominick and Duilo, 1996). Regions (like, the North Central with three (3) crop commodities, North West four (4) Commodities and South West Two (2) commodities) however, need to compare the opportunity cost of one commodity in terms of other, in other to know which of the commodity to specialize on.

\section{ENTREPRENEURSHIP}

Different authors have given different meanings to this word, but entrepreneurship is simply described as the establishment and management of small business. A wide definition of entrepreneurship is the generation of a business ideal or identification of a business opportunity and putting in place of a business to take advantage of the idea or opportunity within an economy (Adeyanju et al., 2010). An entrepreneur can be simply put as one who establishes and manages a business successfully. The production of goods and services in the most efficient manner has continued to be the only viable and liable option for development, growth and survival of any economy. There is no way we could be talking about entrepreneurship without linking with Small and Medium Scale Enterprises (SMEs), because it has been fully recognized by development experts as the main engine of economic growth and reducing poverty level. From a standing point, SMEs are increasingly recognized as the principal catalyst for achieving equitable and sustainable industrial diversification and dispersal in most countries. Also, SMEs account for well over half of the total share of employment, sale and value added (Udechukwu, 2003; Etim, 2010).

Furthermore, the vital role of SMEs as the only authentic foundation for accelerated industrialization, growth and development as witnessed in all the newly industrialized countries of South East Asia, referred to as Asian Tigers, recognized for its accelerated effect in achieving macro-economic objectives such as full employment, income distribution, development of local technology and stimulation of indigenous entrepreneurship, mitigation of rural-urban migration, support and linkage of the entire industrial sector by training of semi-skilled and non-skilled manpower as well as the manufacturing and supply of spare parts and raw materials to large scale industries (Etim, 2010). Entrepreneurship is very interesting because many people want to establish small businesses but certain questions are in their minds which are yet to be satisfied or given good answers to. Because of these questions, some are out there still in paid employment and some are not in any employment but cannot take the bold entrepreneurial step because of the fear of failure which results from lack of entrepreneurship knowledge.

Also, the ability of government is recognized towards the development of SMEs from the point that the government try to set up some programmes that can achieve this, through some of the multi-sectoral programmes such as; National Directorate of Employment, which consist of four main programmes: (a) The Vocational Skills Development Programmes; (b) The Special Public Works Programme; (c) The Small Scale Enterprise Programme; and (d) The Agricultural Employment Programme.

The Directive of Food, Road and Rural Infrastructure which supports mainly rural Infrastructure projects and The Better life programme, which support a multitude of programmes targeted at women including;

(i) Agriculture and extension Services,

(ii) Educational and Vocational Training.

(iii) Cottage Industries and Food Processing. 
Table 1. Regions with absolute cost advantage in food crop production in Nigeria.

\begin{tabular}{|c|c|c|}
\hline Regions & States & Commodities \\
\hline \multirow{7}{*}{ North Central } & Benue & Rice and Cassava \\
\hline & FCT & - \\
\hline & Kogi & Sugar cane, Tomato, Cassava, Oil and Cocoa \\
\hline & Kwara & Rice, Sugar cane and Tomato \\
\hline & Niger & Tomato, Sugar cane and Rice \\
\hline & Nassarawa & - \\
\hline & Plateau & - \\
\hline \multirow{6}{*}{ North East } & Adamawa & Sugar cane and Tomato \\
\hline & Bauchi & Wheat \\
\hline & Borno & Wheat and Jatropha \\
\hline & Gombe & Cotton \\
\hline & Taraba & Rice, Sugar cane, Tomato and Cassava \\
\hline & Yobe & Wheat \\
\hline \multirow{7}{*}{ North West } & Jigawa & Wheat, Cotton, Jatropha and Groundnuts \\
\hline & Kebbi & Jatropha, Wheat and Rice \\
\hline & Kaduna & Groundnuts \\
\hline & Kano & Groundnuts, Jatropha, Cotton, Tomato, Sugar cane, Wheat and Rice \\
\hline & Kastina & Wheat, Tomato, Cotton, Jatropha and Groundnuts \\
\hline & Sokoto & Groundnuts, Jatropha and Rice \\
\hline & Zamfara & Wheat, Sugar cane, Cotton and Tomato \\
\hline \multirow{5}{*}{ South East } & Abia & Oil palm and Rubber \\
\hline & Anambra & Rice and Oil palm \\
\hline & Ebonyi & Oil palm and Rice \\
\hline & Enugu & Cassava \\
\hline & Imo & Rubber, Oil palm and Cassava \\
\hline \multirow{6}{*}{ South West } & Ekiti & Cocoa \\
\hline & Lagos & - \\
\hline & Ondo & Cassava, Rubber and Cocoa \\
\hline & Ogun & Rice, Cotton, Cocoa and Rubber \\
\hline & Osun & Cocoa \\
\hline & Oyo & Cotton, Cocoa and Cassava \\
\hline \multirow{6}{*}{ South South } & Akwa Ibom & Oil palm \\
\hline & Bayelsa & - \\
\hline & Cross River & Cocoa, Oil palm and Cassava \\
\hline & Delta & Rubber and Rice \\
\hline & Edo & Rice, Cocoa, Rubber and Oil palm \\
\hline & Rivers & Oil palm and Rice \\
\hline
\end{tabular}

Source: Federal Ministry of Agriculture and Water Resources, National Food Security Programme.

(iv) Primary Health Care Delivery and

(v) Enlightenment $\backslash$ Awareness; and

(vi) Cooperatives.

Others are;

(a) Manufacturing Sector Programme; (b) Small scale Enterprises to promote the Growth of SMEs in Nigeria, small Scale Industries Through easier access to bank credit, artisan technology and the provision of appropriate infrastructural facilities.

Adeyanju et al. (2010) opined that, the questions which usually counter the thought of the establishing businesses 


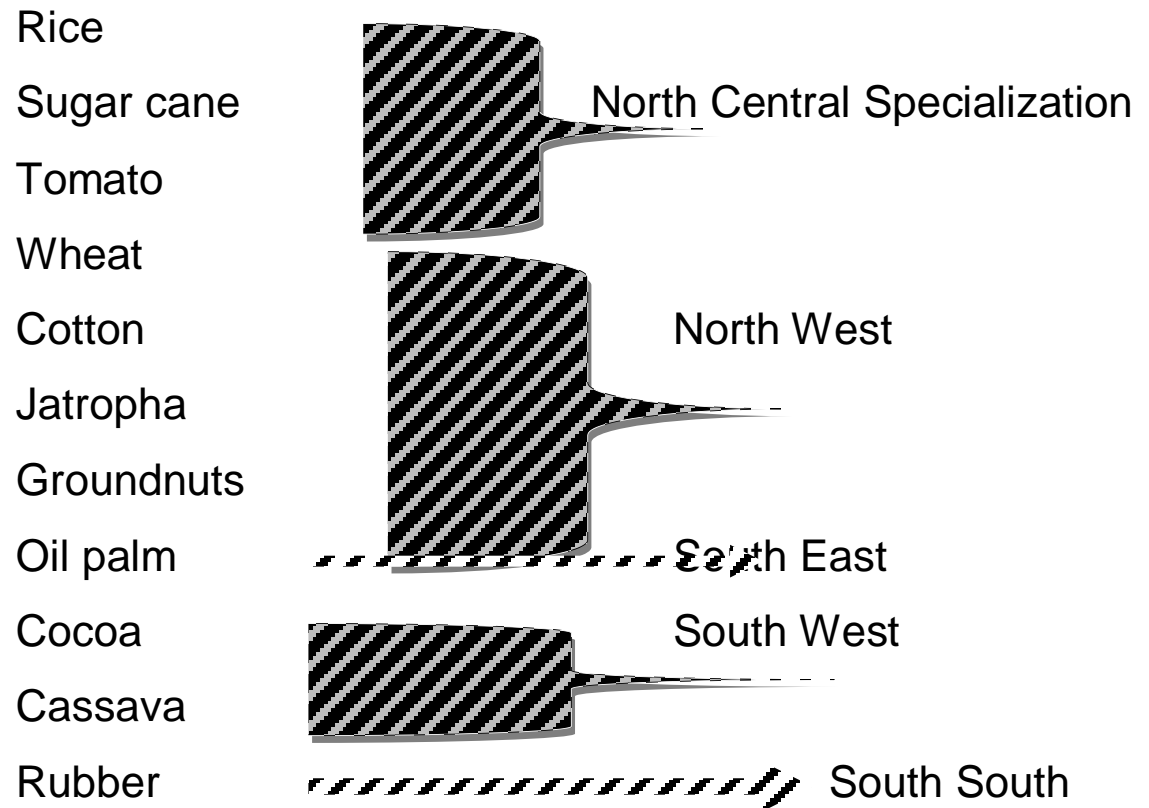

Figure 1. Crops which Nigeria should focus and specialized on.

range from how to start, how to run and run the business successfully. But what they left behind is access to funds and if there are easy access to funds, the onus is how many banks are willing to lend and if there are little banks it is done at high interest rate. Where answers are not provided for these questions, it would be difficult to actualize one's desire to business establishments.

\section{Way forward on SMEs}

The way forward could be gotten by answering the above stated questions. Therefore, answers to these can be gotten through practice and theory. By practice, we mean practical learning through working experience and skill acquisition, while theoretical means referred to educative learning or study of entrepreneurship; this could be achieved by the government in formulating a policy that all Nigeria Higher Institutions of learning should include in their curriculum the basic knowledge of entrepreneurship and vocational studies as shown in Table 2.

\section{TECHNOLOGY TRANSFER}

Technology is the systematic knowledge and action, usually of industrial process but applicable to any recurrent activity. The Federal Ministry of science and technology describe 'technology' on the way of doing things through the application of knowledge derived from systematic investigations of natural and devices indispensable. Hence, the ministry also described technology transfer as absorption of technological knowledge or skills based on the experience and lor specific methods of approaches to resolution of problems with sole purpose of utilizing the resultants acquired knowledge for replication of similar devises and method in difference location.

In dealing with technology transfer, there are two (2) dimensions, the first dimension involves the traditional technology of the absorption, and diffusion and updating of locally generated technology. The second dimension is based on the adaptation, acquisition, absorption and diffusion of foreign technology.

Following the view of Daniel and Jonathan (2009) on the constraints facing technology transfer which are: Patenting, cost, secretive policies, delay tactics, resource scarcity, etc. he buttress further that the constraints have tendered to act as cogs in the wheel of successful achievement of the desired objectives; that the foreign multinational companies who possess the technologies being sought for, often make the patenting, which must be paid in hard currencies rather prohibitive. The fact that new factories have been built in Nigeria with indigenous personnel employed in low-level engineering services and Managerial post is not guarantee that technology would be transferred to Nigerians. Also, the monopoly of technological know-how is perhaps the critical demarcation between developed and developing countries as well as the basic resources in question including: energy, food and water and all these has undergone a sequence of crisis over the past 3 decades.

In conclusion of the analysis of Daniel and Jonathan (2009) was that, the transfer of technology in practical terms is not as feasible as it is usually postulated. There should therefore be a greater reliance on indigenous 
Table 2. List of entrepreneurship and vocational studies to be included in Nigeria Tertiary Institutions.

\begin{tabular}{cll}
\hline S/N & Entrepreneurship studies & Vocational studies \\
\hline 1. & General Management and Human Resources & Fashion Designing and Accessories \\
2. & Entrepreneurship and Business Management & Catering Services and Confectioneries \\
3. & Accounting for Business Management & Computer Maintenance and Servicing \\
4. & Investment, Marketing and Purchasing Management & Textile Design \\
5 & & Wood Work \\
6 & & Production of Fruit Juice and Non-Alcoholic Beverages \\
6 & & Fish Farming \\
8 & & Livestock and Poultry Production \\
\hline
\end{tabular}

It should be noted that amongst the eight (8) vocational studies, student are to offer one (1) of their choice beginning from year 1 to their final year.

technological education and alternative options to enable Nigeria make a break-through in technological and industrial development, which we agreed with him, that it will to a great extent create employment and as well curb the issue of insecurity in the nation at large. Therefore, if Nigeria must develop technological, then a leaf must be borrowed from the experiences of Japan, Brazil and China.

\section{Conclusion and Summary}

The security menace in Nigeria is due to the fact that $80 \%$ of Nigeria wealth is in the possession of $10 \%$ of the population mostly by the politicians. A lot of money and powers are so much in politics, given rise to everybody in the participation of politics, no matter what will take them to get there. Hence, problems all-round the nation mostly during the election. It was also found out that most individuals in the violence/riot are within the purview of the youths without employment (area boys) which are harmed to rig election, at the end those arms were not recovered which they will in turn use to threaten the nation. This could only be controlled by taking necessary measures in ensuring that those regions with comparative and absolute advantage in the production of crop commodities are fully funded by the Federal Government and trade those commodities within regions which will be well supervised and administered by the Governor-General and to make advantage of those crops by exporting them.

The Nigerian economy, since the early seventies has been depended on oil products as a result of the enormity of revenue generated from oil, every little attention has been paid to the proper development of the industrial sector (Etim, 2010) and also serve as raw materials for industrial sector to increase their production capacity and in-turn require labour to meet their demand. Thus, since the organized manufacturing sector is made up of over 95\% SMEs in Nigeria more than ever before, hence, there is need for the country to fine tune it industrial policy and align it with other development strategies so that SMEs could compete favorably with the products of emerging economies and that of developed world, especially to account for increase annual Gross Domestic Product (GDP) growth rate of at least $12.4 \%$. Also, there must be sincere and improved investment in technological education and technological research institute (such as National Office for Technology acquisition programmes (NOTAP) and technology piracy process whereby competent Nigerian technician can undergo a foreign training and modify it to suit the Nigerian culture (Daniel and Jonathan, 2009).

Nigeria is a consumption country, which means that Nigeria is not producing. The provision of the above stated elements will assist in creating the enabling environment for competiveness and growth of SMEs in Nigeria and optimize the eradication of insecurity in Nigeria to the barest minimum.

\section{REFERENCES}

Adeyanju HI, Okusanya OA, Ajayi KO (2010). Entrepreneurship and Business Management. Tunigraphic Prints, Ogun State, Nigeria.

Alademerin EA, Odusina OA (2009). Land Use in Agriculture. Royal Link Press, Ogun State, Nigeria.

Daniel IO, Jonathan OA (2009). Essentials of Science Education. Galaxy Publishers Nigeria Limited. pp. 63-104.

Dominick S, Eugene AD (1996). Schuam's Outline of Theory and Problems of Principles of Economics. 2nd Edition.

Etim EO (2010). Promoting Small Scale and Medium Scale Enterprises in Nigeria: A Panacea for Realization of Financial Systems Strategies (FSS) 2020. Int. J. Econ. Dev. Res. Investment. 1(2 and 3): 142 149.

Federal Ministry of Agriculture and Water Resources: National Food Security Programme. pp. $27-28$.

Udechukwu FN (2003). Central Bank of Nigeria (CBN) Seminar on Small and Medium Industries Equity Investment Scheme (SMIEIS). Lagos, CBN Training Centre.

Wakil BZ (2012). Poverty, Unemployment and Urban Poor in Nigeria. Ramat J. Manage. Sci. Technol., 1:140-144. 